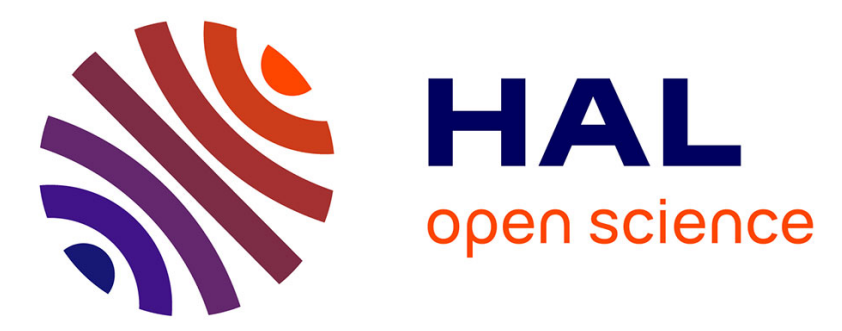

\title{
Landscape metrics for characterization of forest landscapes in a sustainable management framework: Potential application and prevention of misuse
}

Emilio R. Diaz-Varela, Manuel F. Marey-Pérez, Antonio Rigueiro-Rodriguez, Pedro Álvarez-Álvarez

\section{To cite this version:}

Emilio R. Diaz-Varela, Manuel F. Marey-Pérez, Antonio Rigueiro-Rodriguez, Pedro Álvarez-Álvarez. Landscape metrics for characterization of forest landscapes in a sustainable management framework: Potential application and prevention of misuse. Annals of Forest Science, 2009, 66 (3), 10.1051/forest/2009004 . hal-00883396

\section{HAL Id: hal-00883396 https://hal.science/hal-00883396}

Submitted on 1 Jan 2009

HAL is a multi-disciplinary open access archive for the deposit and dissemination of scientific research documents, whether they are published or not. The documents may come from teaching and research institutions in France or abroad, or from public or private research centers.
L'archive ouverte pluridisciplinaire HAL, est destinée au dépôt et à la diffusion de documents scientifiques de niveau recherche, publiés ou non, émanant des établissements d'enseignement et de recherche français ou étrangers, des laboratoires publics ou privés. 


\title{
Landscape metrics for characterization of forest landscapes in a sustainable management framework: Potential application and prevention of misuse
}

\author{
Emilio R. Diaz-VARElA ${ }^{1 *}$, Manuel F. MAREY-PÉREZ ${ }^{1}$, Antonio RigueIRo-RodrigueZ ${ }^{2}$, \\ Pedro ÁlVAREZ-ÁlVAREZ ${ }^{2}$ \\ ${ }^{1}$ Department of Agroforestry Engineering, University of Santiago de Compostela, Spain \\ ${ }^{2}$ Department of Vegetal Production, University of Santiago de Compostela, Spain
}

Keywords:

landscape indices /

scale /

pattern analysis /

sustainable forest management /

FORSEE project

Mots-clés :

indices de paysage /

échelle /

modèle d'analyse /

gestion durable des forêts /

projet FORSEE
(Received 19 October 2008; accepted 6 June 2009)

\begin{abstract}
- The use of landscape indices in the analysis of forest landscapes offers great potential for integration of spatial pattern information in management processes, but requires understanding of the limitations and correct interpretation of results. In this sense, awareness of scale effects on landscape indices is essential, especially when the data available is restricted to low-resolution maps.

- In this study, developed within the framework of the FORSEE project, the objective was to define accurately the potential usefulness of applying landscape indices to low-resolution maps commonly used in forestry studies. Landscape indices were applied to two maps differing in spatial resolution, and subsets were defined for three spatial extensions. Correlation analysis and comparison of the results were carried out to enable identification of the most suitable indices for use with low resolution data.

- The analysis enabled identification of the least scale-dependent indices, which are thus more useful for extrapolating results from low-resolution data. In general terms, diversity and edge indices provided the best results.

- We conclude that some (but not all) of the landscape indices can be used to analyse low-resolution maps with acceptable results. Additional advice is made to prevent misuse of the application of landscape indices.
\end{abstract}

Résumé - Indices quantitatifs de paysage pour une caractérisation des paysages forestiers dans le cadre d'une gestion durable : application potentielle et prévention de mauvaise utilisation.

- L'utilisation d'indices de paysage dans l'analyse des paysages forestiers offre un grand potentiel pour l'intégration d'informations de modèles spatiaux dans les processus de gestion, mais exige la compréhension des limitations et une interprétation correcte de résultats. Dans ce sens, la conscience des effets d'échelle sur les indices de paysage est essentielle, particulièrement quand les données disponibles sont limitées aux cartes de basse résolution.

- Dans cette étude, développée dans le cadre du projet FORSEE, l'objectif était de définir précisément l'utilité potentielle d'application des indices de paysage aux cartes de basse résolution, généralement utilisées dans les études de sylviculture. Les indices de paysage ont été appliqués à deux cartes différant par la résolution spatiale et les sous-ensembles ont été définis pour trois extensions spatiales. Une analyse de corrélation et la comparaison des résultats ont été effectuées pour permettre l'identification des indices les plus appropriés pour une utilisation avec des données de basse résolution. - L'analyse a permis l'identification des indices les moins dépendants de l'échelle, qui sont ainsi plus utiles pour extrapoler les résultats de données de basse résolution. En termes généraux, la diversité et des indices de bord ont fourni les meilleurs résultats.

- Nous concluons que certains (mais pas tous) indices de paysage peuvent être utilisés pour analyser les cartes de basse résolution avec des résultats acceptables. Un conseil supplémentaire est fait pour prévenir une mauvaise utilisation des indices de paysage.

\footnotetext{
*Corresponding author: emilio.diaz@usc.es
} 


\section{INTRODUCTION}

Sustainable forestry management pursues multifunctionality of forest ecosystems and landscapes, and assumes that forests can assume a variety of functions in addition to productive functions, namely: carbon sequestration, watershed protection, biodiversity, recreation, cultural and social uses, etc. (Andersson et al., 2004; Von Gadow et al., 2000). In order to maintain or enhance such multifunctionality, the spatial complexity or heterogeneity of forest landscapes has been reported to be a critical factor (Bengtsson et al., 2000; Franklin and Forman, 1987; Lindenmayer et al., 2000) as it can have positive effects on both the ecological (ecosystem stability, species diversity...) and productive (increased yield, resistance to pests) characteristics of forests. Consequently, assessment of the spatial heterogeneity of forest landscapes should be included in the indicators used in sustainable forestry management across Europe.

To improve the situation regarding indicators for sustainable forest management, the EU funded the INTERREG III-B FORSEE project to assess the relevance, feasibility and costs of such indicators. The indicators analysed in the project include six criteria (carbon stocks, health, productive functions, biological diversity, soil and water protection, and socioeconomic functions). The study and characterization of the heterogeneity and complexity of forest ecosystems, as well as their fragmentation, are included within biological diversity, by means of the application of landscape indices or metrics.

Application of landscape metrics, defined as quantitative indices that describe structures or patterns in landscapes (O'Neill et al., 1988), has numerous precedents in different fields (Botequilha and Ahern, 2002; Botequilha et al., 2006; Gustafson, 1998; Hargis et al., 1998; Hoover and Parker, 1991; O'Neill et al., 1988). Specifically, landscape metrics have been used for the analysis of forestry related issues, such as: fragmentation and other forest transformations (Löfman and Kouki, 2003; McAlpine and Eyre, 2002; Riitters et al., 2002; Trani and Giles, 1999); the effects of wildfires on forest cover (Gonzalez et al., 2000; Lloret et al., 2002; Romme, 1982); differentiation between native and introduced forests (Saura and Carballal, 2004), and to address wildlife habitat concerns in developing decision-making support tools in forest ecosystem management (Falcao and Borges, 2005). Nevertheless, and despite their extensive use, the precise meaning of each metric may be uncertain and the interpretation of the results complicated by different factors (Corry and Nassauer, 2005; Li and $\mathrm{Wu}, 2004)$. One of the questions that requires better understanding is the response of metrics to changes in scale. This problem has been approached in numerous studies with respect to both spatial extent (Saura and Martínez-Millán, 2001; Turner et al., 1989; Wu et al., 2002) and grain size or resolution (Baldwin et al., 2004; Saura, 2004; Turner et al., 1989; $\mathrm{Wu}, 2004)$, which are considered as two fundamental components of the scale (Gustafson, 1998). Specifically, the effect of the resolution of cartographic data on landscape metrics has been investigated in the search for mathematical relationships across scales, which could enable prediction of the behaviour of indices with changes in scale. Studies have included vary- ing the resolution of categorical maps (Baldwin et al., 2004; Turner et al., 1989), use of remote sensed data (Frohn, 1998; Frohn and Hao, 2006; Saura, 2004), and development of artificial landscape maps simulated with neutral models (Li et al., 2005; Saura, 2002). In general it was found that the trends in results can vary greatly when applied to different map extensions and/or resolutions (depending on the type of metric and the way it is applied), and that in order to avoid misleading results, such resolutions must match the capability of the landscape metric to reflect the characteristics of the spatial heterogeneity. These are important constraints considering that much readily available spatial data is often of low resolution, and its application could lead to problems due to the confusing effects that low resolution and aggregation of data have on the results of landscape metrics (Baldwin et al., 2004; Benson and MacKenzie, 1995; Saura, 2004). On the other hand, the development of fine-grained maps for large extensions may involve costs that are difficult for many forestry or environmental related organizations and enterprises. Despite these shortcomings, landscape metrics can be considered for use as indicators of forest heterogeneity by planners and technicians once their scientific soundness and technical reliability, as well as their comprehensibility and low-cost implementation have been improved.

The objective of this study was to evaluate the potential usefulness of the application of landscape indices to lowresolution maps commonly used in forestry studies, by the identification of possible inaccuracies derived from the application of a series of landscape indices to coarse-scaled cartographic data commonly used in regional and sub-regional forestry studies. The specific aim was to identify which indices demonstrate most robustness and scale-independence in their application to the aforementioned data sources, in order to improve the quality of the analysis of heterogeneity in forested landscapes. The approach used was to compare the results of the application of indices to an example of a categorical map developed under an EFICS protocol, (see Material and methods) and to a high-resolution categorical map developed for this project. Correlation analysis of the results of each metric in several subsets of the maps was applied to search for common trends in the results derived from both sources. This allowed us to define and finally recommend which indices can be used, and the situations in which they can be used, for the analysis of heterogeneity in low-resolution cartographical data.

The reference framework for the study was biological diversity, as defined in the above-mentioned FORSEE project, in which a series of landscape indices were specified for the characterization of forest fragmentation, heterogeneity and connectivity.

\section{MATERIAL AND METHODS}

\subsection{Study area}

The study area (see Fig. 1) includes two municipalities, Aranga $\left(119 \mathrm{~km}^{2}\right)$ and Guitiriz $\left(293 \mathrm{~km}^{2}\right)$, respectively in the provinces of A 


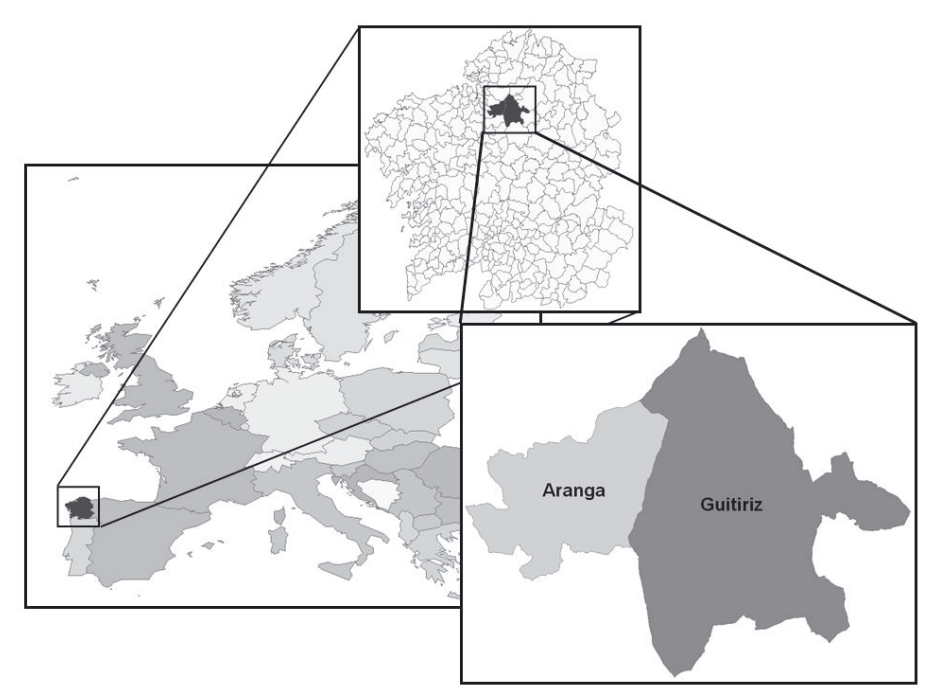

Coruña and Lugo (Galicia, NW Spain). The area is characterized by uneven relief, with the altitude ranging from 400 to $700 \mathrm{~m}$. More than $30 \%$ of the area consists of forest zones, noteworthy because of the extensions of native deciduous forests and Eucalyptus spp. and Pinus spp. plantations.

\subsection{Cartography used}

Two digital, vectorial format cartography sources were used: The Forest Map of Spain, developed at a national level, and a project specific map, developed for the study area, which was used as the Ground-Truth Map (hereafter referred to as GTM).

The Forest Map of Spain (FMS) is developed by the Spanish Ministry of Environment, and updated on a ten yearly basis as support for the National Forest Inventory. It follows the EU regulations established by the EFICS (European Forestry Information and Communication System) regarding actions addressing the availability of detailed data about forests in all European Union member states (Päivinen and Köhl, 2005). As such, it was considered here as an adequate example for testing the behaviour of landscape metrics in maps currently used for the assessment of forest statistics. The Forest Map of Spain is currently the most comprehensive work developed at the national level as regards forest mapping. It is developed at a cartographic scale of 1:50000, the Minimum Mapping Unit (MMU) is $25000 \mathrm{~m}^{2}$ for forest land and $62500 \mathrm{~m}^{2}$ for other land use classes, and it includes alpha-numerical information about fifteen descriptors related to forest ecology and structure. The map is developed from the interpretation of aerial photographs, followed by vectorization of the delineated land-cover polygons over high resolution ortho-photographs and codification of the polygons with their landuse code, and the accuracy of data is checked in the field.

The Ground Truth Map (GTM) was developed for the project study area by means of analogical photo-interpretation of highresolution orthophotographies, supported by a cadastral vector map. As a result, a map of a cartographic scale of 1:2000, with an MMU of $25 \mathrm{~m}^{2}$, was obtained. Even when the accuracy of the GTM was not evaluated, the standards followed in previous studies (see Marey, 2003) were applied in elaboration of the map. Such studies showed a global accuracy of $89.2 \%$ when a contingency matrix was used at species-level definition of the typological level. The accuracy of the map was considered sufficient for it to be used as ground truth data in the comparison with the Forest Map of Spain.

A EUNIS (European Union Nature Information System) habitat legend of 13 classes was used as a reference for re-classification of the data sources under a single unified factor, and included:

- Surface standing waters (C1),

- Temperate shrub heathland (F4),

- Hedgerows (FA),

- Riparian Salix, Alnus and Betula woodland (G1-1),

- Acidophilous Quercus-dominated woodland (G1-8),

- Eucalyptus plantations (G2-81),

- Highly artificial coniferous plantations (G3-F),

- Mixed deciduous and coniferous woodland (G4),

- Coppice and early-stage plantations (G5-7),

- Arable land and market gardens (I1),

- Transport networks (J4),

- Buildings of cities, towns and villages (J1),

- Low density buildings (J2).

Thematic resolution is coarser in the FMS, in which just 8 of the 13 classes are represented, owing to the aggregation effect imposed by the MMU. Thus, low density buildings, hedgerows, small ponds, etc. are not represented. The thematic resolution can strongly influence the results of the indices (Baldwin et al., 2004; Buyantuyev and $\mathrm{Wu}, 2007)$, and the GTM was therefore re-classified in both an 8class legend (or "Equal Typological Legend") and a 13-class legend (or "Extended Typological Legend") for the analysis.

After reclassification, the maps were converted into raster format, to facilitate calculation of indices. A resolution of $1 \times 1 \mathrm{~m}$ of pixel size was adopted for rasterization.

\subsection{Landscape metric analysis}

The need to obtain values for landscape metrics with the FRAGSTATS software (McGarigal et al., 2002) is established in criterion 4 of the FORSEE project (biodiversity). Metrics are classified in terms of the specific characteristics to be analysed in the 


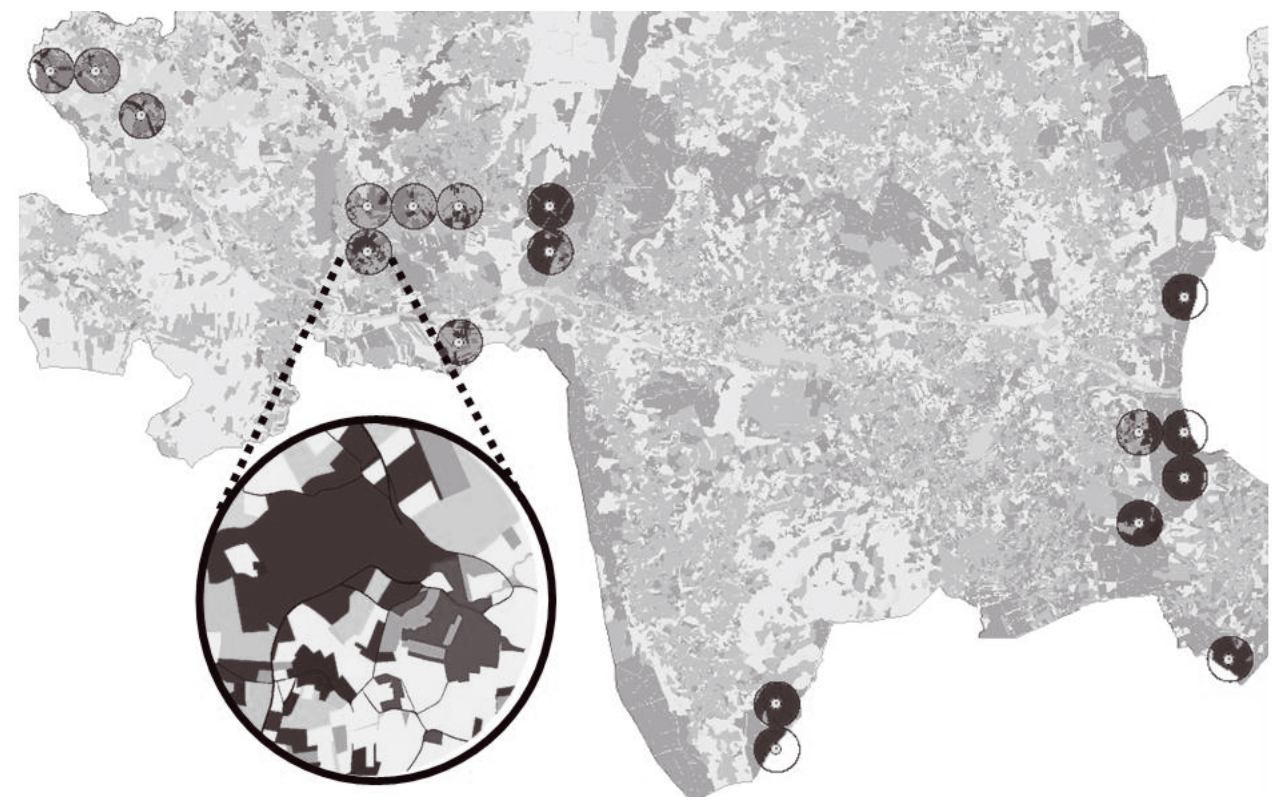

Figure 2. Distribution of plots, and detail of one of the $500 \mathrm{~m}$ buffer areas (GTM).

landscape, i.e. fragmentation, heterogeneity and connectivity. In the study, 12 metrics were added to the 10 recommended in the FORSEE project to enhance the analysis of results.

As a standard procedure for calculation in the project, nonoverlapping buffer areas of $500 \mathrm{~m}$ radius were defined around reference points, and the landscape pattern inside them was characterized with the landscape metrics (See Fig. 2). This procedure was complemented in the present study by calculation of metrics in buffer areas of 1000 and $1500 \mathrm{~m}$ radius, in the belief that the effects of the variation in extension could clarify the behaviour of some of the indices. In these areas, overlapping was allowed, as the intention was comparison of pairs of map sections corresponding to the two different sources, and not between buffer areas of the same data source, in which case partial replication of results could be expected. Three different buffer sizes were used despite the sensitivity of the indices to changes in extent (Baldwin et al., 2004; Saura and Martínez-Millán, 2001; Wu, 2004; Wu et al., 2002), as the comparisons were made among series of data calculated in buffers of equal extension. The metrics finally used were:

- Fragmentation: This group includes both composition metrics (related to the number and relative importance of elements in the landscape) and configuration metrics (related to those characteristics concerning geometrical aspects of landscape elements). Composition metrics included number of patches (NP); mean patch size (AREA_MN); and number of classes (N_CLASS) as initially defined in the FORSEE project; patch density (PD) was also added to the set. Configuration metrics included edge density (ED) and area-weighted mean shape index (SHAPE_AM), in the project; total edge (TE), standard deviation of patch size (AREA_SD), mean shape index (SHAPE_MN), standard deviation of shape index (SHAPE_SD), mean fractal dimension (FRAC_MN), standard deviation of fractal dimension (FRAC_SD), mean perimeter-area ratio (PARA_MN) and standard deviation of perimeter-area ratio (PARA_SD) were also calculated.
- Heterogeneity: Shannon's diversity (SHDI) and evenness (SHEI) indices were initially considered, and Simpson's diversity index (SIDI), modified Simpson's diversity index (MSIDI), Simpson's evenness index (SIEI), modified Simpson's evenness index (MSIEI), and number of classes (N_CLASS) were added.

- Connectivity: Mean nearest neighbour distance between two patches of the same forest type (ENN_MN) was complemented with deviation of nearest neighbour distance (ENN_SD)

Details on the mathematical expressions and meaning of the indices calculated by FRAGSTATS can be found on the corresponding website (McGarigal et al., 2002). The buffer areas were defined in this study with 18 sampling points established in the National Forest Inventory as a reference for the centre of the buffers. Landscape metrics were then calculated, for the portions of the maps corresponding to the buffer areas. The indices were calculated at landscape level, i.e. considering the full arrangement of patches in the calculation, without qualitative distinction among different classes.

\subsection{Statistical analysis}

Spearman's rho Test was used to determine which landscape indices are related in the two types of cartography used (FMS and GTM). Spearman's rho is a rank-order correlation coefficient that measures association at the ordinal level (Spearman, 1904). It is a nonparametric version of the Pearson correlation based on ranks of the data rather than actual values (SPSS Inc., 2005). The use of ranks eliminates the sensitivity of the correlation test to the function linking the pairs of values (Pagano and Gauvreau, 2001). In particular, the standard correlation test is used to find linear relations between test pairs, but the rank correlation test is not restricted in this way. Spearman's coefficient of rank correlation, denoted by $r_{s}$, was calculated by application of the following equation (Eq. (1)):

$$
r_{s}=1-\frac{6 \sum d_{i}^{2}}{n \cdot\left(n^{2}-1\right)}
$$



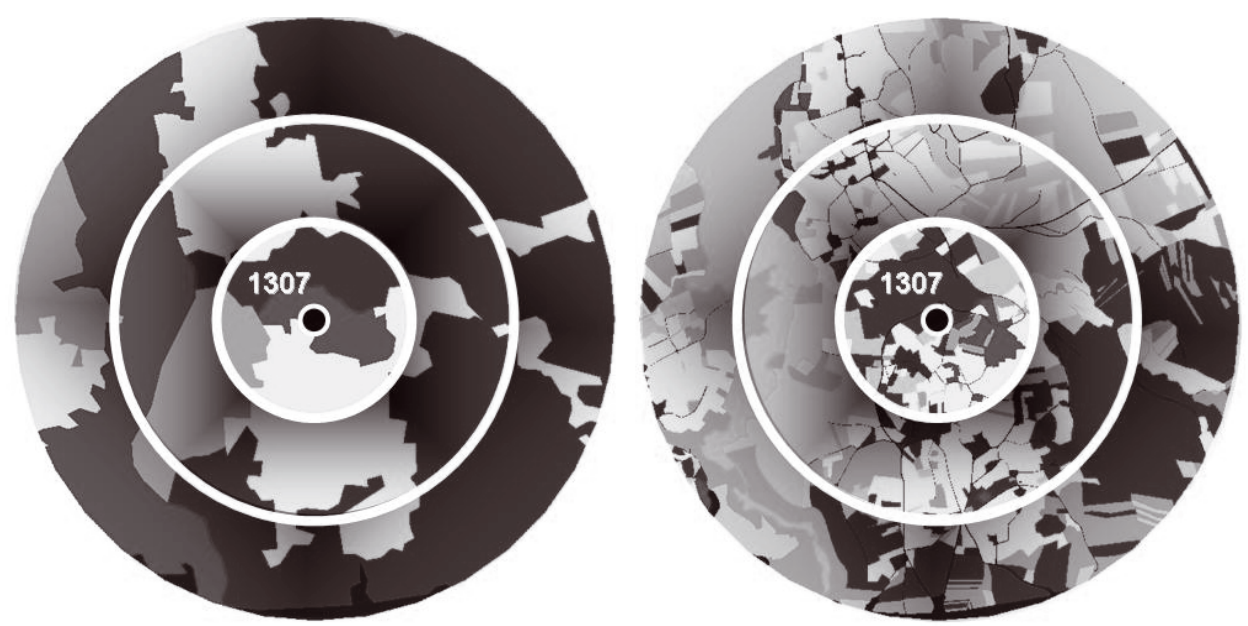

Figure 3. Buffer areas around plot 1307. Left, FMS; right, GTM. The radii of the circular areas (from inner to outer) are 500,1000 and $1500 \mathrm{~m}$.

Where $d_{i}$ is the difference in the ranks given to the values of the two variables for each item of data. This is only an equivalent equation when there are no tied ranks, and if there are only a few of these, the equation provides an adequate approximation.

\section{RESULTS}

\subsection{Misclassification errors and aggregation}

During the analysis, two factors were identified in the FMS that could affect the results in the comparison process. Firstly, the presence of misclassified patches, i.e., where codification of the element in the map does not correspond to the real world. As the indices were calculated at the landscape level, there was no qualitative distinction among classes, and the influence can be only quantitative, and directly affect those metrics related to the number of classes and/or diversity. Secondly, the effects caused by aggregation. These were assumed to occur, as the differences between the two data sources as regards MMU were known. However, it should be emphasised that the aggregation of spatial data affected composition and configuration of the map, and thus affected the results of the indices as shown in the following paragraph.

\subsection{Application of metrics}

Direct numerical comparison in absolute terms of the results of landscape metrics calculated in the FMS and the GTM shows large differences among most of the indices, independently of the size of the buffer area. As an example, the graphical and numerical differences for the buffer areas located around plot No. 1307 are shown in Figure 3 and Table I.

These differences are especially noteworthy in the composition indices chosen to assess fragmentation. For instance, differences between the maps for NP or PD reflect strong divergence between the two map sources, with higher values obtained with GTM. Similar trends were observed with ED and TE, as well as AREA_MN. Values also diverge depending on the GTM legend, with an obvious decline in NP, PD, TE and ED, and increase in AREA_MN, in the values calculated for the "equal" typological legend.

A regards indices accounting for spatial configuration, it is important to note the different behaviour of PARA_MN, and both SHAPE_MN and FRAC_MN. Values of the former varied greatly depending on the data source, whereas the latter two were closer in range. However, the area weighted shape index SHAPE_AM revealed important differences between the two data sources. Differences among values concerning GTM legends are minimal in all metrics showing spatial complexity. ENN_MN, related to connectivity, provided very different values depending on the data source used, including those related to the typological legend.

Finally, diversity indices showed important differences between data sources. Such differences were greater for SHDI and MSIDI. Furthermore, all the diversity indices showed a decrease in the GTM equal typological legend, and a greater decrease in MSIDI.

\subsection{Statistical analysis}

The analysis involving comparison among Spearman's Rho values revealed correlation between FMS and GTM for some of the indices. Nevertheless, only TE, N_CLASS, and all the diversity indices showed statistical significant correlations between the two maps at any of the three scales used. Other indices, such as NP, ED, AREA_MN, SHAPE_AM, PARA_SD, ENN_SD, FRAC_MN and FRAC_SD, showed some degree of correlation at one or two of the scales used in the analysis. AREA_SD, SHAPE_SD, and ENN_MN did not show any trace of correlation among the results for GTM and FMS at any of the scales. The values for all the calculated metrics are shown in Table II.

The response of the indices to the correlation analysis can be classified as follows:

(a) Values decrease sharply with the increase in the extension of the buffer area. This is the case of metrics that 
Table I. Example of the results for the analysis of the two map sources and the three buffers.

\begin{tabular}{|c|c|c|c|c|c|c|c|c|c|}
\hline \multirow{3}{*}{ No. 1307} & \multicolumn{3}{|c|}{ Buffer distance $=500 \mathrm{~m}$} & \multicolumn{3}{|c|}{ Buffer distance $=1000 \mathrm{~m}$} & \multicolumn{3}{|c|}{ Buffer distance $=1500 \mathrm{~m}$} \\
\hline & \multirow{2}{*}{ FMS } & \multicolumn{2}{|c|}{ GTM } & \multirow{2}{*}{ FMS } & \multicolumn{2}{|c|}{ GTM } & \multirow{2}{*}{ FMS } & \multicolumn{2}{|c|}{ GTM } \\
\hline & & Ext. T. L. & Eq. T. L. & & Ext. T. L. & Eq. T. L. & & Ext. T. L. & Eq. T. L. \\
\hline NP & 7 & 117 & 87 & 12 & 340 & 218 & 16 & 614 & 427 \\
\hline PD & 8.91 & 148.97 & 110.77 & 3.84 & 108.77 & 69.74 & 2.28 & 87.30 & 60.71 \\
\hline TE & 4931 & 28582 & 26016 & 15487 & 102336 & 92963 & 32714 & 198218 & 182088 \\
\hline ED & 62.78 & 363.92 & 331.25 & 49.55 & 327.40 & 297.41 & 46.52 & 281.84 & 258.91 \\
\hline AREA_MN & 11.22 & 0.67 & 0.90 & 26.05 & 0.92 & 1.43 & 43.96 & 1.15 & 1.65 \\
\hline AREA_SD & 10.21 & 1.77 & 2.05 & 33.01 & 2.65 & 3.32 & 80.09 & 4.67 & 5.64 \\
\hline SHAPE_MN & 1.59 & 1.98 & 2.10 & 1.79 & 1.94 & 2.12 & 2.12 & 1.95 & 2.08 \\
\hline SHAPE_AM & 1.80 & 2.38 & 2.33 & 2.26 & 2.91 & 2.94 & 2.95 & 3.32 & 3.34 \\
\hline SHAPE_SD & 0.26 & 1.91 & 2.17 & 0.45 & 2.32 & 2.86 & 0.62 & 2.09 & 2.46 \\
\hline FRAC_MN & 1.08 & 0.00 & 1.15 & 1.11 & 1.16 & 1.16 & 1.13 & 1.16 & 1.17 \\
\hline FRAC_SD & 0.02 & 0.00 & 0.12 & 0.06 & 0.13 & 0.15 & 0.04 & 0.13 & 0.15 \\
\hline PARA_MN & 399.13 & 3683.77 & 3510.77 & 1222.35 & 4139.83 & 3528.94 & 685.39 & 5014.01 & 4948.74 \\
\hline PARA_SD & 371.77 & 5972.68 & 6807.04 & 2799.17 & 7167.00 & 7543.18 & 953.05 & 8620.24 & 9444.82 \\
\hline ENN_MN & 215.42 & 42.57 & 28.98 & 173.80 & 42.93 & 45.86 & 159.59 & 40.71 & 42.32 \\
\hline ENN_SD & 128.36 & 80.30 & 41.94 & 111.59 & 104.64 & 102.51 & 120.58 & 95.91 & 101.22 \\
\hline SHDI & 1.29 & 1.79 & 1.56 & 1.25 & 1.93 & 1.66 & 1.28 & 1.96 & 1.75 \\
\hline SIDI & 0.70 & 0.78 & 0.75 & 0.68 & 0.81 & 0.76 & 0.68 & 0.83 & 0.80 \\
\hline MSIDI & 1.21 & 1.52 & 1.38 & 1.15 & 1.65 & 1.44 & 1.13 & 1.76 & 1.61 \\
\hline SHEI & 0.93 & 0.72 & 0.75 & 0.90 & 0.78 & 0.80 & 0.71 & 0.79 & 0.84 \\
\hline SIEI & 0.94 & 0.85 & 0.85 & 0.91 & 0.88 & 0.87 & 0.81 & 0.90 & 0.91 \\
\hline MSIEI & 0.88 & 0.61 & 0.66 & 0.83 & 0.66 & 0.69 & 0.63 & 0.71 & 0.77 \\
\hline N_CLASS & 4 & 12 & 8.00 & 4 & 12 & 8.00 & 6 & 12 & 8.00 \\
\hline
\end{tabular}

Ext.T.E.: Extended Typological Legend (13 classes); Eq.T.E.: Equal Typological Legend (8 classes).

include density values such as PD and ED, composition metrics such as AREA_MN, and configuration metrics such as SHAPE_AM. The values of these parameters show significant correlations at any of the typological scales for the lower buffer size, but the degree of correlation decreases with the wider extensions. There are various reasons for this, depending on the metrics concerned (see Discussion), and in general terms the correlation was higher for the extended typological legend in GTM.

(b) Values with more or less consistent response in the correlation. These may show some variation or a decrease in the absolute values for the correlation, but in general such correlation is significant throughout the different extensions. This response was shown by TE, and by the "diversity" metrics, such as N_CLASS, SHDI, SIDI, SHEI, SIEI, MSIDI and MSIEI. The correlation was generally slightly higher for the Extended Typological Legend in TE, and for the Equal Typological Legend in the other metrics.

(c) Inconsistent response. Correlation varies with no apparent trend related to the extension. This behaviour was shown by FRAC_MN, FRAC_SD, PARA_SD, ENN_SD and to some degree by NP.

\section{DISCUSSION AND CONCLUSIONS}

\subsection{Scale issues and the results in landscape indices}

The information displayed by FMS and GTM for the same geographical area is organized differently. The differences in organization of the information are due to the different criteria used for their production, and are closely dependent on the inherent characteristics of the elements that structure landscapes, such as their shape, abundance or spatial distribution. Generalization is imposed in the FMS by its resolution and the MMU used, causing aggregation of spatial information and resulting in a shift or 'jump' in the scale to the represented pattern from that in the GTM.

This affects the results of the indices, which depend on the characteristics of the composition and configuration of the represented landscape, and consequently the resolution at which is represented. This dependence on the resolution of the information analysed can be interpreted as a "scale problem", one of the means adopted by the Modifiable Areal Unit Problem (MAUP) (Jelinski and Wu, 1996; Marceau, 1999), which occurs when a spatial data set is combined into a smaller number of units of greater surface area. This effect was previously reported elsewhere as regards the effects of changes in resolution for landscape metrics (Wu et al., 2002). Two main consequences of MAUP were observed in the present study: The misleading effect implied in the interpretation of results for those indices directly related to quantification of patches and their area (i.e., NP, PD, AREA_MN), or the number and proportion of classes (N_CLASS, and the indices of diversity), and the inability of the metrics to capture those characteristics of the landscape pattern or process that occur at scales finer than that reflected by the map elements. For instance, in our case, fine-grained fragmentation associated with small, scattered patches cannot be described by indices such 
Table II. Values of Spearman's Rho indices showing statistical correlations. Results are shown for the three different buffer areas used, and comparing the two typological levels for the calculation. Asterisk (*) indicates significant correlation at $P=0.05$ (bilateral); double asterisk (**) indicates significant correlation at $P=0.01$ (bilateral).

\begin{tabular}{|c|c|c|c|c|c|c|}
\hline \multirow{3}{*}{ Landscape metric } & \multicolumn{4}{|c|}{ Spearman's Rho } & & \\
\hline & \multicolumn{2}{|c|}{ Buffer distance $=500 \mathrm{~m}$} & \multicolumn{2}{|c|}{ Buffer distance $=1000 \mathrm{~m}$} & \multicolumn{2}{|c|}{ Buffer distance $=1500 \mathrm{~m}$} \\
\hline & Exp. & Eq. & Exp. & Eq. & Exp. & Eq. \\
\hline NP & $0.498^{*}$ & 0.438 & $0.602 * *$ & $0.557 *$ & 0.465 & 0.361 \\
\hline PD & $0.486 *$ & 0.430 & 0.268 & 0.188 & 0.011 & -0.98 \\
\hline $\mathrm{TE}$ & $0.696 * *$ & $0.665^{* *}$ & $0.626^{* *}$ & $0.610 * *$ & $0.657 * *$ & $0.606^{* *}$ \\
\hline ED & $0.669 * *$ & $0.642 * *$ & 0.385 & 0.373 & 0.259 & 0.079 \\
\hline AREA_MN & $0.486^{*}$ & 0.430 & 0.268 & 0.188 & 0.011 & -0.98 \\
\hline AREA_SD & 0.102 & 0.080 & 0.236 & 0.158 & 0.030 & -0.005 \\
\hline SHAPE_MN & -0.430 & -0.350 & -0.314 & 0.002 & 0.077 & 0.346 \\
\hline SHAPE_AM & $0.711 * *$ & $0.622 * *$ & 0.278 & 0.257 & -0.391 & -0.410 \\
\hline SHAPE_SD & -0.096 & -0.034 & -0.437 & -0.321 & -0.267 & -0.038 \\
\hline FRAC_MN & -0.420 & 0.006 & $0.589 *$ & $0.536^{*}$ & -0.201 & 0.183 \\
\hline FRAC_SD & -0.264 & 0.027 & $0.546^{*}$ & $0.525^{*}$ & 0.048 & 0.036 \\
\hline PARA_MN & 0.373 & 0.348 & 0.273 & 0.342 & -0.011 & -0.90 \\
\hline PARA_SD & 0.377 & 0.402 & $0.573 *$ & $0.519 *$ & -0.038 & -0.032 \\
\hline ENN_MN & 0.147 & 0.137 & 0.106 & 0.117 & 0.152 & 0.042 \\
\hline ENN_SD & 0.262 & 0.170 & $0.613 * *$ & $0.539^{*}$ & 0.263 & 0.150 \\
\hline SHDI & $0.801 *$ & $0.808^{* *}$ & 0.395 & $0.482 *$ & 0.364 & $0.662 * *$ \\
\hline SIDI & $0.816^{* *}$ & $0.824 * *$ & $0.643 * *$ & $0.738 * *$ & $0.558^{*}$ & $0.761 * *$ \\
\hline MSIDI & $0.816^{* *}$ & $0.824 * *$ & $0.643 * *$ & $0.738 * *$ & $0.548^{*}$ & $0.761 * *$ \\
\hline SHEI & $0.752 * *$ & $0.783^{* *}$ & $0.564 *$ & $0.503 * *$ & 0.317 & $0.552 *$ \\
\hline SIEI & $0.822 * *$ & $0.839 * *$ & $0.610 * *$ & $0.643 * *$ & $0.633 * *$ & $0.759 * *$ \\
\hline MSIEI & $0.801 * *$ & $0.790 * *$ & $0.682 * *$ & $0.529 * *$ & $0.595 * *$ & $0.692 * *$ \\
\hline N_CLASS & $0.682 * *$ & $0.660 * *$ & $0.565^{* *}$ & $0.700 * *$ & 0.341 & $0.521^{*}$ \\
\hline
\end{tabular}

as ENN_MN when applied to FMS, as the computation of Euclidean distances in the absence of small patches affects the overall results.

As a consequence, there were important differences between the results obtained with the indices used in the FMS and in the GTM. Even when this is an obvious effect taking into account the divergence in the information displayed by each data source, it is important to underline that the patterns or processes analysed with landscape indices should be consistent with the resolution of the data sources. In general terms, the MMU set the lower limit for resolution in data in vectorial maps, with extent being the upper limit. Therefore, detection of landscape patterns is constrained by such limits (Corry and Nassauer, 2005; Thompson and McGarigal, 2002). In addition to the spatial scale, the typological scale is a source of variation in the values of the metrics. This is evident from the present results, especially when the results associated with the extended and the equal typological legends in GTM are compared. The variation in the values of landscape metrics associated with the change in typological or thematic scale is well documented in the literature, and has been specifically addressed in recent studies (Bailey et al., 2007a; 2007b; Buyantuyev and Wu, 2007; Huang et al., 2006), in which it has generally been concluded that metrics behave differently, both quantitatively and qualitatively, depending on the extension analysed.

\subsection{Correlation in results from FMS and GTM}

Once the above considerations have been taken into account, pattern analysis with landscape metrics can provide useful results. Correlation analysis may help to reveal the possibilities for correct use of landscape indices in low-resolution vectorial forest maps, such as FMS. In the present study it enabled identification of metrics that retrieve information about the landscape pattern when they are interpreted not by their absolute value, but by their relative variation across scales. Nevertheless, even when interesting results are apparently obtained in the correlation analysis, they must be interpreted cautiously. With the first type of results (correlation decreasing with the extension of buffer zones) the values obtained for AREA_MN and SHAPE_AM are considered to be affected to a great extent by the methodology. The position of the stand (i.e., the centre of the buffer) was deliberately placed inside forest landscapes, and therefore large forested patches are likely to be found in the immediate range of the stand, which is reflected by the similar "patchiness" patterns in the two data sources analysed. As the extension increases, the landscape pattern may include different, non-forested elements, and there is a higher probability that the GTM will include patches smaller than the MMU of the FMS. Thus, the sensitivity of AREA_MN, (and consequently in SHAPE_AM, due to its area-weighting) to changes in the spatial pattern affects the correlation between scales. 
Density metrics, PD and ED, are highly sensitive to extent in correlation analysis, a characteristic that is not shared by the indices representing their absolute values, NP and TE, respectively. This may be due to the differences reported by $\mathrm{Wu}$ et al. (2002) regarding the responses to changes in extension between PD and TE. The metrics NP and FRAC_MN were classified as erratic in their response to the scale because of the impossibility in finding a clear trend in the evolution of the scale-related results. TE is included in the group of the metrics that show a more consistent response across scales, together with the whole group of diversity indices, including SHDI, SIDI, SHEI, SIEI, MSHEI and MSIEI. This type of response is obviously of more interest for the objectives of this study. TE reflects nicely the complexity of the landscape at the two scales analysed, probably because measuring the total border length between patches involves less exposure to the area effects described above.

The diversity measures selected for the analysis are mostly based on the contribution (i.e. proportion) of each different habitat in the studied portions of landscape. They are quite sensitive to the type of legend used, because of the method of calculation, which affects the total proportion of each habitat. In this case, the higher values of correlation were observed when equal-legend maps were compared. The best results were provided by SIDI and MSIDI, probably because of the straightforward calculations involved (based respectively on the sum of the squares of the proportion of classes, and on the logarithm of the sum).

\subsection{Use of landscape metrics for assessing fragmentation, heterogeneity and connectivity at different scales}

The improper use of landscape indices occurs when there is inconsistency between the structure represented on the map and the process that we want to analyse with the metric. Despite interesting results obtained with fine-grained maps (Bailey et al., 2007b; Martin-Garcia et al., 2006), it is difficult to infer biodiversity characteristics in forest landscapes from absolute results of landscape indices, especially when applied to low resolution maps. Correspondingly, for the sake of reliability in the analysis, it must be clear that not all aspects of the complexity of forest landscapes can be characterised by application of landscape metrics. Nevertheless, their relative values can be used for assessing some aspects of such complexity.

Among the three groups of indices used in the FORSEE project to represent forest pattern complexity, namely fragmentation, connectivity and heterogeneity, the latter, composed of diversity metrics, showed more scale-independence in the results than the other indices when considering relative values. Thus, diversity metrics are recommended for the analysis of heterogeneity, taking into account that the different indices do not describe the same landscape properties (Lausch and Herzog, 2002; Nagendra, 2002). For instance SHDI may be more appropriate for taking into consideration rare cover types, and conversely SIDI may be more appropriate when the interest is focused on dominant cover types. Fragmentation in- dices in this study only include TE as acceptable regarding scale-independence, and none of the connectivity indices are acceptable. From the results obtained we then recommend the use of edge metrics, especially those reporting absolute values (TE), for the characterization of landscape configuration. The use of contrast edge metrics, such as the Total Edge Contrast Index (Botequilha and Ahern, 2002; Botequilha et al., 2006; McGarigal et al., 2002) is recommended for enhancing ecological analysis of fragmentation. However, other aspects of fragmentation or connectivity, in areas where such factors depend on fine-grained landscape elements (like tiny patches or corridors) require greater resolution. To solve this, we suggest the use of multi-scale strategies, with low resolution cartography to assess the general characteristics of landscape heterogeneity and configuration, and to identify heterogeneous spots, and derivation of high-resolution analysis in the specific spots, thereby decreasing the costs of the analysis. Similar approaches have been used in diverse examples in other fields of forest and ecosystem management (see e.g., Klijn, 1991; Nakamura et al., 2005; Sims et al., 1995).

In summary, from the results obtained here, some additional advice can be given in order to prevent misuse of landscape indices when applied to low-resolution, vectorial forest maps. In general, such maps can be used to:

- Support definition of forest landscape units;

- Describe the general structure of the landscape pattern, particularly when comparisons are made between landscapes;

- Estimate regional (supra-local) forest diversity;

- Give geographical sense to general forest statistics;

- Define spatially the general evolution in main forest areas, including those aspects inferred from their shape, by comparing maps of the same geographical area at different times.

... And should not be used to:

- Estimate accurately the total forest area in highly fragmented landscapes (such as that in the case studied), because of the accumulation effect of small forest patches in the overall results;

- Assess general forest connectivity, as the effect of the patches ignored due to the resolution of data may be missed;

- Assess fragmentation at local levels.

Acknowledgements: This study was supported by the European Union funded INTERREG III-B project 020-FORSEE (Sustainable management of forests: a European network of pilot zones for putting this into operational effect), and by a research contract with the University of Santiago de Compostela supported by the Galician regional government (Isidro Parga Pondal (PGIDIT) programme). We also thank Dr Christine Francis for correcting the English grammar of the text.

\section{REFERENCES}

Andersson F., Birot Y., and Päivinen R., 2004. Towards the sustainable use of Europe's forests - Forest ecosystems and landscape research: 
Scientific challenges and opportunities. EFI Proceedings No. 49, European Forest Institute.

Bailey D., Billeter R., Aviron S., Schweiger O., and Herzog F., 2007a. The influence of thematic resolution on metric selection for biodiversity monitoring in agricultural landscapes. Landsc. Ecol. 22: 461473.

Bailey D., Herzog F., Augenstein I., Aviron S., Billeter R., Szerencsits E., and Baudry J., 2007b. Thematic resolution matters: Indicators of landscape pattern for European agro-ecosystems. Ecological Indicators 7: 692-709.

Baldwin D.J.B., Weaver K., Schnekenburger F., and Perera A.H., 2004. Sensitivity of landscape pattern indices to input data characteristics on real landscapes: implications for their use in natural disturbance emulation. Landsc. Ecol. 19: 255-271.

Bengtsson J., Nilsson S.G., Franc A., and Menozzi P., 2000. Biodiversity, disturbances, ecosystem function and management of European forests. For. Ecol. Manage. 132: 39-50.

Benson B.J. and MacKenzie M.D., 1995. Effects of sensor spatial resolution on landscape structure parameters. Landsc. Ecol. 10: 113-120.

Botequilha Leitao A. and Ahern J., 2002. Applying landscape ecological concepts and metrics in sustainable landscape planning. Landsc. Urban Plann. 59: 65-93.

Botequilha Leitao A., Miller J., Ahern J., and McGarigal K., 2006. Measuring landscapes. A planner's handbook, Island Press, Washington, $245 \mathrm{p}$.

Buyantuyev A. and Wu J., 2007. Effects of thematic resolution on landscape pattern analysis. Landsc. Ecol. 22: 7-13.

Corry R.C. and Nassauer J.I., 2005. Limitations of using landscape pattern indices to evaluate the ecological consequences of alternative plans and designs. Landsc. Urban Plann. 72: 265-280.

Falcao A.O. and Borges J.G., 2005. Designing decision support tools for Mediterranean forest ecosystems management: a case study in Portugal. Ann. For. Sci. 62: 751-760.

Franklin J.F. and Forman R.T.T., 1987. Creating landscape patterns by forest cutting: Ecological consequences and principles. Landsc. Ecol. 1: $5-18$.

Frohn R.C., 1998. Remote sensing for landscape ecology. New metric indicators for monitoring, modeling, and assessment of ecosystems, Lewis Publishers, Boca Raton, 99 p.

Frohn R.C. and Hao Y., 2006. Landscape metric performance in analyzing two decades of deforestation in the Amazon Basin of Rondonia, Brazil. Remote Sens. Environ. 100: 237-251.

Gonzalez J.R., Palahí M., and Pukkala T., 2000. Integrating fire risk considerations in forest management planning in Spain - a landscape level perspective. Landsc. Ecol. 20: 957-970.

Gustafson E.J., 1998. Quantifying Landscape Spatial Pattern: What Is the State of the Art? Ecosystems 1: 143-156.

Hargis C.D., Bissonette J.A., and David J.L., 1998. The behavior of landscape metrics commonly used in the study of habitat fragmentation. Landsc. Ecol. 13: 167-186.

Hoover S.R. and Parker A.J., 1991. Spatial components of biotic diversity in landscapes of Georgia, USA. Landsc. Ecol. 5: 125-136.

Huang C., Geiger E.L., and Kupfer J.A., 2006. Sensitivity of landscape metrics to classification scheme. Int. J. Remote Sens. 27: 2927-2948.

Jelinski D.E. and Wu J., 1996. The modifiable areal unit problem and implications for landscape ecology. Landsc. Ecol. 11: 129-140.
Klijn F., 1991. Hierarchical classification of ecosystems: a tool for susceptibility analysis and quality evaluation for environmental policy. In: Ravera, O. (Ed.), Terrestrial and aquatic ecosystems. Perturbation and recovery, Ellis Horwood, London, pp. 80-89.

Lausch A. and Herzog F., 2002. Applicability of landscape metrics for the monitoring of landscape change: issues of scale, resolution and interpretability. Ecol. Indic. 2: 3-15.

Li H. and Wu J., 2004. Use and misuse of landscape indices. Landsc. Ecol. 19: 389-399.

Li X.Z., He H.S., Bu R.C., Wen Q.C., Chang Y., Hu Y.M., and Li Y.H., 2005. The adequacy of different landscape metrics for various landscape patterns. Pattern Recogn. 38: 2626-2638.

Lindenmayer D.B., Margules C.R., and Botkin D.B., 2000. Indicators of biodiversity for ecologically sustainable forest management. Conserv. Biol. 14: 941-950.

Lloret F., Calvo E., Pons X., and Diaz-Delgado X., 2002. Wildfires and landscape patterns in the Eastern Iberian peninsula. Landsc. Ecol. 17: $745-759$.

Löfman S. and Kouki J. 2003. Scale and dynamics of a transforming forest landscape. For. Ecol. Manage. 175: 247-252.

Marceau, D.J., 1999. The scale issue in social and natural sciences. Can. J. Remote Sens. 25: 347-356.

Marey M.F., 2003. Tenencia de la tierra en Galicia: Modelo para la caracterización de los propietarios forestales. Doctoral Thesis. University of Santiago de Compostela.

Martin-Garcia J., Herve J., and Diez J.J., 2006. Landscape metrics as surrogates for bird assemblages in biodiversity indicators. Indicators for Sustainable forest management in cultivated forests: International Conference FORSEE Project Final Meeting, 11-13 December 2006, Porto (Portugal).

McAlpine C.A. and Eyre T.J., 2002. Testing landscape metrics as indicators of habitat loss and fragmentation in continuous eucalypt forests (Queensland, Australia). Landsc. Ecol. 17: 711-728.

McGarigal K., Cushman S.A., Neel M.C., and Ene E., 2002. FRAGSTATS: Spatial Pattern Analysis Program for Categorical Maps. University of Massachussetts. Available on the internet, URL: www.umass.edu/landeco/research/fragstats/fragstats.html.

Nagendra H., 2002. Opposite trends in response for the Shannon and Simpson indices of landscape diversity. Applied Geography 22: 175186.

Nakamura F., Inahara S., and Kaneko M., 2005. A hierarchical approach to ecosystem assessment of restoration planning at regional, catchment and local scales in Japan. Landscape and Ecological Engineering 1: 43-52.

O’Neill R.V., Krummel J.R., Gardner R.H., Sugihara G., Jackson B., DeAngelis D.L., Milne B.T., Turner M.G., Zygmunt B., Christensen S.W., Dale V.H., and Graham R.L., 1988. Indices of landscape pattern. Landsc. Ecol. 1: 153-162.

Pagano M. and Gauvreau K., 2001. Principios de Bioestadística. Thomson Learning, México D.F., 525 p.

Päivinen R. and Köhl M., 2005. European Forest Information and Communication System (EFICS), Technical Report 17, European Forest Institute. Available on the internet, URL: http://www.efi.fi/ publications/technical-reports/17.html (last visit 23/07/2007).

Riitters K.H., Wickham J.D., O'Neill R.V., Jones K.B., Smith E.R., Coulston J.W., Wade T.G., and Smith J.H., 2002. Fragmentation of continental United States forests. Ecosystems 5: 815-822. 
Romme W.H., 1982. Fire and landscape diversity in subalpine forests of Yellowstone National Park. Ecol. Monogr. 52: 199-221.

Saura S., 2002. Effects of minimum mapping unit on land cover data spatial configuration and composition. Int. J. Remote Sens. 23: 48534880 .

Saura S., 2004. Effects of remote sensor spatial resolution and data aggregation on selected fragmentation indices. Landsc. Ecol. 19: 197-209.

Saura S. and Carballal P., 2004. Discrimination of native and exotic forest patterns through shape irregularity indices: an analysis in the landscapes of Galicia, Spain. Landsc. Ecol. 19: 647-662.

Saura S. and Martínez-Millán J., 2001. Sensitivity of landscape pattern metrics to map spatial extent. Photogram. Eng. Remote Sens. 67: $1027-1036$.

Sims R.A., Mackey B.G., and Baldwin K.A., 1995. Stand and landscape level applications of a forest ecosystem classification for northwestern Ontario, Canada. Ann. For. Sci. 52: 573-588.

Spearman C., 1904. The proof and measurement of association between two things. Am. J. Psychol. 15: 72-101.
SPSS Inc., 2005. SPSSTM version14.0.1. Statistical software. Statistical Products and Service Solutions Inc., Chicago.

Thompson C.M. and McGarigal K., 2002. The influence of research scale on bald eagle habitat selection along the lower Hudson River, New York (USA). Landsc. Ecol. 17: 569-586.

Trani M.K. and Giles R.H., 1999. An analysis of deforestation: Metrics used to describe pattern change. For. Ecol. Manage. 114: 459-470.

Turner M.G., O’Neill R.V., Gardner R.H., and Milne B.T., 1989. Effects of changing spatial scale on the analysis of landscape pattern. Landsc. Ecol. 3: 153-162.

Von Gadow, K., Pukkala, T. and Tome, M., 2000. Sustainable Forest Management. Kluwer Academic Publishers, Dordrecht, 356 p.

Wu J., 2004. Effects of changing scale on landscape pattern analysis: scaling relations. Landsc. Ecol. 19: 125-138.

Wu J., Shen W., Sun W., and Tueller P.T., 2002. Empirical patterns of the effects of changing scale on landscape metrics. Landsc. Ecol. 17: 761-782. 